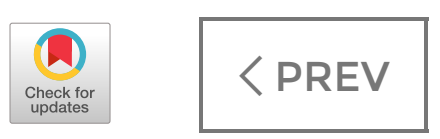

Full

Published Online: 09 May 2008

\title{
Decalcifying Protocol of Odontocete Ear Samples with RDO®
}

The Journal of the Acoustical Society of America 123, 3619 (2008); https://doi.org/10.1121/1.2934832

Maria Morell

- Laboratori d'Aplicacions Bioacústiques (Universitat Politècnica de Catalunya), avda. Rambla Exposició s/n, 08800 Vilanova i la Geltrú, Spain, maria.morell@lab.upc.edu Eduard Degollada more... 


\section{Topics -}

\section{ABSTRACT}

The study of the organ of Corti is essential to assess the impact of underwater noise on cetaceans. While classical histology techniques (including EDTA decalcification) have been previously considered, the process is time consuming and artifacts, probably directly deriving from the protocol, often appear and difficult the analysis. However, no matter the choice of the analysis technique, one of the challenging step after extraction and fixation of the samples is to decalcify the bone envelope to access the cochlea without damaging the soft tissues. Here, we propose to use a fast commercial decalcifier (RDOß). 103 ears from 12 different odontocetes species stranded in the Mediterranean, Spanish North Atlantic and North Sea have been used to precisely determine the decalcification time. Specifically, the species processed were: Phocoena phocoena $(n=45)$, Stenella coeruleoalba $(n=12)$, Stenella frontalis $(n=12)$, Tursiops truncatus $(n=13)$, Delphinus delphis $(\mathrm{n}=4)$, Kogia simus $(\mathrm{n}=3)$, Kogia breviceps $(\mathrm{n}=2)$, Globicephala macrorhynchus ( $n=3)$, Globicephala melas $(n=2)$, Steno bredanensis $(n=4)$, Lagenodelphis hosei $(n=2)$ and Ziphius cavirostris $(\mathrm{n}=1)$. Depending on the species, the decalcification time ranged from several hours to a few days, allowing a subsequently faster observation of the cochlear structures through routine microscope techniques. 


\section{Resources}

AUTHOR

LIBRARIAN

ADVERTISER

General Information

ABOUT

CONTACT

HELP

PRIVACY POLICY

TERMS OF USE

FOLLOW AIP PUBLISHING:

f $y$ in 